\title{
EFFECT OF THERMOCYCLING ON SURFACE ROUGHNESS AND SPRINGBACK PROPERTIES OF DIFFERENT ORTHODONTIC ARCH WIRES: AN IN VITRO COMPARATIVE STUDY
}

\author{
Marwa Shamaa* and Sayed Ghorab ${ }^{* *}$
}

\begin{abstract}
Objective: Comparative evaluation of surface roughness and springback properties of stainless steel (SS), nickel-titanium (NiTi), copper nickel-titanium (CuNiTi) and Teflon-coated NiTi orthodontic archwires before and after thermocycling.

Materials and Methods: A total number of 360 specimens were utilized in this study. For each type of wire, specimens were divided into three groups as follow; Group 1 (control): as-received archwires, Groups 2 and 3: specimens were subjected to thermocycling (500 cycles and 1000 cycles, respectively). Surface roughness ( $\mathrm{Ra}$ ) was determined by using a profilometer. Flexural modulus of elasticity (E) and yield strength (YS) of the wires were measured using a three-point bending test in a universal testing machine. The springback ratio (YS/E) was calculated for each wire. Data were statistically analyzed using ANOVA and Bonferroni post hoc tests $(\alpha=.05)$.
\end{abstract}

Results: For all types of wire, the highest surface roughness was noted with 1000 cycles, followed by 500 cycles and the lowest surface roughness was detected in control group. No significant difference in surface roughness between control and $500 \mathrm{TC}$ group was detected for all types of wire. After thermocycling, the highest surface roughness was noted in Teflon coated NiTi, followed by CuNiTi and NiTi and the lowest values was detected in SS. There was a significant difference in the springback ratio after thermocycling regimens for SS, NiTi and Teflon coated NiTi only $(\mathrm{P}<0.001)$.

Conclusion: The thermocycling process can induce changes in surface roughness and springback properties of orthodontic archwires. Stainless steel archwire displayed the least amount of surface roughness after thermocycling and we recommend its utilization in sliding mechanics to reduce friction during orthodontic tooth movement. In spite of higher surface roughness of NiTi-based archwires, the properties of higher springback and wide range of action make them appropriate choices for the clinicians during various stages of orthodontic treatment.

KEYWORDS: Thermocycling; surface roughness; springback properties; orthodontic archwires.

* Lecturer, Department of Orthodontics, Faculty of Dentistry, Mansoura University, Egypt.

** Lecturer, Dental Biomaterials Department, Faculty of Dentistry, Mansoura University, Egypt. 


\section{INTRODUCTION}

Orthodontic archwire is regarded as the corner stone on which the orthodontic art and science are established. These archwires persist in the oral cavity for a prolonged duration. Thus, they are expected to undergo some biodegradation in the continually changeable oral environment. ${ }^{1}$

One of the chief breakthroughs in orthodontic materials research is the availability of various alloys for orthodontic arch wires giving rise to a major progress in the field of mechanotherapy. ${ }^{2}$ Among orthodontic arch wires, stainless steel (SS) represents one of the most extensively utilized materials due to its ease of welding, high formability and great resistance to corrosion. SS wire is considered a reference material used for comparing the properties of different wire alloys due to its low spring-back and friction values. ${ }^{3}$ Nickel-titanium (NiTi) arch wires becomes prevalent to an increasing extent due to their capability to deliver light constant forces and to display complete recovery even after deformation. ${ }^{4}$ Recently, refinement of the nickeltitanium alloy was done by addition of copper $(\mathrm{Cu})$ to the alloy to improve the physical and mechanical characteristics. $^{5}$

Orthodontic metallic materials are generally composed of alloys incorporating different base metals such as cobalt, nickel, chromium, titanium and molybdenum. ${ }^{6}$ Since orthodontic treatment may be extended for long time, a significant patient's concern is the aesthetic appearance of the appliance. To accomplish this demand, metal esthetic coated arch wires become increasingly popular. ${ }^{7,8}$

Numerous characteristics should be taken into account in the seeking for ideal archwire. Among them, the surface roughness of archwires which is of utmost importance as it affects their performance and biocompatibility. ${ }^{9}$ It can also impact the sliding mechanics through modifying the friction coefficient. ${ }^{10}$ In addition to surface characteristics, springback is another essential parameter in tooling design and attaining the desirable configuration of archwire. The archwire bending process plays a key role in orthodontics. After load release, the archwire in the bending process tries to restore its original shape due to elastic stresses. ${ }^{11}$ Therefore, a study on the springback of different archwires is a substantial issue.

During orthodontic treatment, the arch wires are subjected to abundant factors and variables that exist in the patient's mouth like consuming cold and hot food and beverages. ${ }^{12}$ These temperature changes can produce microstructural changes in orthodontic alloys due to thermal stresses, remarkably changing their physical properties. Thermocycling has been introduced as an artificial ageing process which is used to produce the temperature alterations that can take place in the oral cavity when taking hot and cold diet or drinks. ${ }^{13}$ Few studies have tackled the effect of thermocycling on the characteristics of different orthodontic arch wires. ${ }^{14,15}$ Therefore, the current comparative study aimed at evaluating the influence of different thermocycling regimens on the surface roughness and springback properties of various orthodontic archwires. The null hypothesis tested was that thermocycling would not alter the archwires' characteristics.

\section{MATERIALS AND METHODS}

\section{Specimens preparation and grouping}

Four types of commercially available round orthodontic archwires were investigated in this study. A full description of these wires is presented in Table 1. Each wire specimen was 0.016 inches in diameter $\mathrm{x} 40 \mathrm{~mm}$ in length, cut from the straight portion of preformed archwires. A total number of 360 specimens were utilized in this study (180 specimens to test the effect of thermocycling on the surface roughness and another 180 specimens to test its effect on the springback properties). For each test, 45 specimens from each type of wire were divided into three groups ( $N=15 /$ group) as follow; 
TABLE (1): Types, composition and manufacturer of orthodontic arch wires utilizesd in the study

\begin{tabular}{|c|c|c|c|}
\hline Archwire & Composition (wt \%) & Manufacturer & Batch no. \\
\hline SS & $\begin{array}{l}71 \% \mathrm{Fe}, 8 \% \mathrm{Ni} \\
18 \% \mathrm{Cr}, 0.2 \% \mathrm{C}\end{array}$ & Dentaurum, Ispringen, Germany & 98018 \\
\hline NiTi & $\begin{array}{l}54.9 \% \mathrm{Ni}, 44.9 \% \mathrm{Ti}, \\
0.2 \% \mathrm{Cr}\end{array}$ & Ormco, Orange, CA, USA & 071507865 \\
\hline $\begin{array}{l}\text { CuNiTi } \\
27^{\circ} \mathrm{C}\end{array}$ & $\begin{array}{l}49.1 \% \mathrm{Ni}, 45.7 \% \mathrm{Ti}, \\
0.2 \% \mathrm{Cr}, 5 \% \mathrm{Cu}\end{array}$ & Ormco, Orange, CA, USA & 041216838 \\
\hline Teflon-coated NiTi & $\begin{array}{l}52 \% \mathrm{Ni}, 45 \% \mathrm{Ti}, \\
3 \% \mathrm{Cr} \text {, in addition to the coating } \\
\text { layer of polytetrafluoroethylene. }\end{array}$ & $\begin{array}{c}\text { Ortho-Organizers, Inc, } \\
\text { Sanmarcos, California; USA }\end{array}$ & 178133 \\
\hline
\end{tabular}

Group 1 (control): as-received archwires, Groups 2 and 3: specimens were subjected to thermocycling (500 thermal cycles (TC) and 1000 thermal cycles (TC), respectively) between $5^{\circ} \mathrm{C}$ and $55^{\circ} \mathrm{C}$ (Thermocycler THE-1100, SD Mechatronik GmbH, Bayern, Germany), with the wires periodically submerged in each thermal bath for 30 seconds, with 15 seconds at air temperature between submersions to reproduce temperature alterations that can take place in the oral cavity when ingesting cold and hot diet and drinks, respectively. Fifteen specimens were selected per group to yield $99 \%$ power in the results of this study based on the results of D'anto et al. ${ }^{16}$ in which the authors found a significant difference in surface roughness between four types of wires (effect size $=.684$, alpha $=5 \%$ ).

\section{Measurement of surface roughness}

Surface roughness was assessed by surface roughness profilometer tester (Surftest SJ-210, Mitutoyo Corporation, Tokyo, Japan,) according to ISO $4287-1997^{17}$ with $5 \mu \mathrm{m}$ diamond tip radius, $0.01 \mu \mathrm{m}$ resolution, $0.5 \mathrm{~mm} / \mathrm{s}$ scanning speed, $1.5 \mathrm{~mm}$ cut-off length and a Gaussian filter. The specimen was fixed under the stylus. The average $\left(\mathrm{R}_{\mathrm{a}}\right)$ was measured by moving the stylus along the surface. Each specimen was tested three times, and the average roughness was calculated in micrometer $(\mu \mathrm{m})$.

\section{Three-point bending test}

All wire specimens were subjected to a threepoint bending test on a Universal Testing Machine (LLOYD instruments, LR 5K, England). They were inserted into the slots of two self-ligated Damon brackets (Ormco) placed $14 \mathrm{~mm}$ apart and glued on a fixture fixed to the base of the testing machine. A steel rod with a bi-beveled chisel end was used to apply compressive force midway between the two poles at a crosshead speed of $0.5 \mathrm{~mm} / \mathrm{min}$ (Figure 1). Each wire specimen was loaded to a deflection of $3 \mathrm{~mm}$. A computer software program (Nexygen-MT Lloyd Instruments) was used to record Load in newtons and deflections in millimeters for each specimen. Flexural stress as a function of flexural strain was measured for

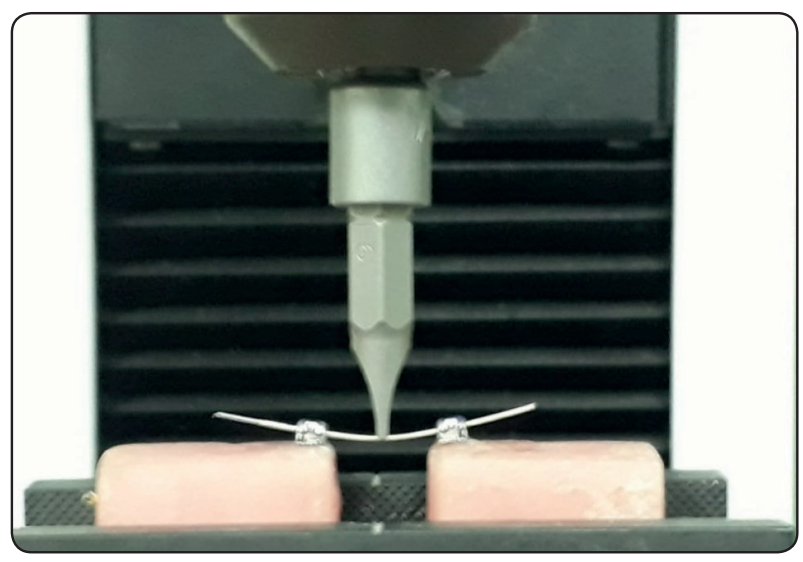

Fig. (1): A close up view of a specimen in 3-point bending test. 
each wire specimen based on the load-deflection curve and the dimensions of the sample. Flexural modulus of elasticity (E) and yield strength (YS) were calculated for each specimen. Springback ratio (YS/E) was calculated for each specimen by dividing yield strength by modulus of elasticity. ${ }^{18}$

\section{Statistical analysis}

Shapiro-Wilk test was used to test the normal distribution of data. The data were parametric and met the normal distribution. Repeated measures ANOVA was used to test significant differences of surface roughness, modulus of elasticity, yield strength and springback ratio between different types of wires (SS, NiTi, Cu NiTi, and Teflon coated NiTi) and between different thermocycling regimens (as-received,500 TC, and $1000 \mathrm{TC}$ ), followed by Bonferroni post hoc test for multiple comparisons. $\mathrm{P}$ value is significant if it was less than .05 .

\section{RESULTS}

\section{Surface roughness}

Comparisons of surface roughness between different types of wires and between thermocycling regimens are presented in Table 2 . For all regimens of thermocycling, there was a significant difference in surface roughness between archwires. The highest surface roughness was noted in Teflon coated NiTi, followed by NiTi and CuNiTi (without difference between the latter two groups) and the lowest surface roughness was detected in SS. There was a significant difference between each two types of wire except between $\mathrm{Ni}$-Ti and $\mathrm{Cu} \mathrm{Ni}-\mathrm{Ti}$. There was a significant difference in surface roughness between thermocycling conditions for all types of wires (Table 2). Multiple comparisons of surface roughness between thermocycling regimens are presented in Figure 2. For all types of wire, the highest surface roughness was noted with 1000 cycles, followed by 500 cycles and the lowest surface roughness was detected in asreceived archwires group. No significant difference in surface roughness between control and $500 \mathrm{TC}$ group was detected for all types of wire.

\section{Modulus of elasticity}

Comparison of modulus of elasticity between different types of wires and between thermocycling conditions are presented in table 3. At 500 and 1000 cycles only, there was a significant difference in modulus of elasticity between archwires. The highest modulus of elasticity was noted in SS, followed by $\mathrm{NiTi}, \mathrm{Cu} \mathrm{NiTi}$, and the lowest modulus of elasticity was detected in Teflon coated Ni-Ti. At 500 cycles, there was no significant difference between NiTi, $\mathrm{Cu}$ NiTi and Teflon coated NiTi. At 1000 cycles, there was no significant difference neither between SS and NiTi nor between $\mathrm{Cu}$ NiTi and Teflon coated Ni-Ti. There was no significant difference in the modulus of elasticity between thermocycling conditions for all types of wire (Table 3). Multiple comparisons of modulus of elasticity between thermocycling regimens are presented in Figure 3

\section{Yield strength}

Comparison of yield strength between different types of wires and between thermocycling conditions are presented in Table 4. There was a significant difference in yield strength at 1000 cycles only. The highest yield strength was observed in NiTi followed by SS then CuNiTi and the lowest yield strength was noted in Teflon coated NiTi. There was no significant difference in yield strength neither between $\mathrm{SS}$ and NiTi nor between $\mathrm{Cu}$ NiTi and Teflon coated NiTi. There was no significant difference in yield strength between thermocycling conditions for all types of wire (Table 4). Multiple comparisons of yield strength between thermocycling conditions are presented in Figure 4.

\section{Spring back ratio}

Comparisons of springback ratio between different types of wires and between thermocycling conditions are presented in Table 5. 
For all thermocycling conditions, there was a significant difference in springback ratio between different types of wires. For control and 1000TC groups, the highest springback ratio was noted in Teflon coated NiTi, followed by NiTi, then $\mathrm{Cu} \mathrm{NiTi}$, and the lowest value was noted in SS. For 500TC group, the highest springback ratio was detected in Teflon coated NiTi, followed by $\mathrm{Cu} \mathrm{NiTi,} \mathrm{then}$ $\mathrm{NiTi}$, and the lowest value was detected in SS. For as-received archwires group, no significant difference between $\mathrm{Ni}-\mathrm{Ti}, \mathrm{Cu} \mathrm{NiTi}$ and SS was noted. For 500 TC group, no difference between $\mathrm{Cu} \mathrm{NiTi}$ and NiTi was noted. For 1000TC group, no difference between $\mathrm{Cu}$ NiTi, NiTi and Teflon coated NiTi was noted. There was a significant difference in springback ratio between thermocycling conditions for SS, NiTi and Teflon coated NiTi only (Table 5). Multiple comparisons of springback ratio between thermocycling regimens are presented in Figure 5. For SS, NiTi and Teflon coated NiTi; the highest springback ratio was noted in as-received group, followed by $1000 \mathrm{TC}$ group and the lowest springback ratio was noted in 500TC group. No significant difference between control and 1000TC groups was observed in SS arch wire. For Ni-Ti, there was no significant difference between control and 500 TC groups. No difference was detected between 500 and 1000TC groups in Teflon coated NiTi arch wire.

TABLE (2): Comparison of surface roughness between different types of wires and effect of different thermocycling conditions.

\begin{tabular}{|c|c|c|c|c|c|c|c|}
\hline & \multicolumn{2}{|c|}{ Control } & \multicolumn{2}{|c|}{$500 \mathrm{TC}$} & \multicolumn{2}{|c|}{$1000 \mathrm{TC}$} & \multirow{2}{*}{$\begin{array}{c}\text { Repeated measures } \\
\text { ANOVA (p value) }\end{array}$} \\
\hline & $X$ & $S D$ & $X$ & $S D$ & $X$ & $S D$ & \\
\hline SS wire & $.061 \mathrm{a}$ & .015 & $.082 \mathrm{a}$ & .073 & $.128 \mathrm{a}$ & .015 & $.049 *$ \\
\hline NiTi & $.228 b$ & .015 & $.277 b$ & .036 & $.354 b$ & .049 & $<.001^{*}$ \\
\hline $\mathrm{Cu}$ NiTi & $.257 \mathrm{~b}$ & .020 & $.269 \mathrm{~b}$ & .031 & $.388 b$ & .039 & $<.001 *$ \\
\hline Teflon_NiTi & $.303 c$ & .060 & $.359 \mathrm{c}$ & .031 & $.405 c$ & .046 & $.004 *$ \\
\hline $\begin{array}{l}\text { Repeated measures ANOVA } \\
\text { (p value) }\end{array}$ & \multicolumn{2}{|c|}{$<.001 *$} & \multicolumn{2}{|c|}{$<.001 *$} & \multicolumn{2}{|c|}{$<.001^{*}$} & \\
\hline
\end{tabular}

$X$; mean, SD; standard deviation, *p is significant at 5\% level of significance. Different letters in the same column indicate a significant difference between different types of wires (Bonferroni test, $p<.05$ )

TABLE (3): Comparison of modulus of elasticity between different types of wires and effect of different thermocycling conditions.

\begin{tabular}{|c|c|c|c|c|c|c|c|}
\hline & \multicolumn{2}{|c|}{ Control } & \multicolumn{2}{|c|}{$500 \mathrm{TC}$} & \multicolumn{2}{|c|}{$1000 \mathrm{TC}$} & \multirow{2}{*}{$\begin{array}{l}\text { Repeated measures } \\
\text { ANOVA ( } p \text { value) }\end{array}$} \\
\hline & $X$ & $S D$ & $X$ & $S D$ & $X$ & $S D$ & \\
\hline SS wire & $25.518 \mathrm{a}$ & 30.067 & $46.225 \mathrm{a}$ & 2.588 & $35.420 \mathrm{a}$ & 36.271 & .13 \\
\hline NiTi & $14.625 \mathrm{a}$ & 2.617 & $14.995 b$ & 1.860 & $25.803 \mathrm{a}$ & 13.082 & .45 \\
\hline $\mathrm{Cu}$ NiTi & $10.788 \mathrm{a}$ & .953 & $10.782 \mathrm{~b}$ & .583 & $10.282 \mathrm{~b}$ & .608 & .99 \\
\hline Teflon_NiTi & $5.070 \mathrm{a}$ & .915 & $6.200 \mathrm{~b}$ & .977 & $6.110 \mathrm{~b}$ & .722 & .99 \\
\hline $\begin{array}{l}\text { Repeated measures ANOVA } \\
\text { (p value) }\end{array}$ & \multicolumn{2}{|c|}{.23} & \multicolumn{2}{|c|}{$.001 *$} & \multicolumn{2}{|c|}{$.020 *$} & \\
\hline
\end{tabular}

$X$; mean, SD; standard deviation, *p is significant at $5 \%$ level of significance. Different letters in the same column indicate a significant difference between different types of wires (Bonferroni test, $p<.05$ ) 
TABLE (4): Comparison of yield strength between different types of wires and effect of different thermocycling conditions.

\begin{tabular}{|c|c|c|c|c|c|c|c|}
\hline & \multicolumn{2}{|c|}{ Control } & \multicolumn{2}{|c|}{500 TC } & \multicolumn{2}{|c|}{$1000 \mathrm{TC}$} & \multirow{2}{*}{$\begin{array}{l}\text { Repeated measures } \\
\text { ANOVA ( } p \text { value) }\end{array}$} \\
\hline & $X$ & $S D$ & $X$ & $S D$ & $X$ & $S D$ & \\
\hline SS wire & $493.548 \mathrm{a}$ & 538.753 & $277.362 \mathrm{a}$ & 15.524 & $689.615 \mathrm{a}$ & 658.876 & .13 \\
\hline NiTi & $356.025 \mathrm{a}$ & 56.349 & $339.568 \mathrm{a}$ & 43.078 & $750.903 a$ & 472.470 & .078 \\
\hline $\mathrm{Cu}$ NiTi & $251.003 \mathrm{a}$ & 4.447 & $264.550 \mathrm{a}$ & 10.001 & $257.893 b$ & 18.363 & .99 \\
\hline Teflon_NiTi & $165.778 \mathrm{a}$ & 13.902 & $171.570 \mathrm{a}$ & 12.152 & $174.170 b$ & 13.749 & .99 \\
\hline $\begin{array}{l}\text { Repeated measures ANOVA } \\
\text { ( } \mathrm{p} \text { value) }\end{array}$ & \multicolumn{2}{|c|}{.40} & \multicolumn{2}{|c|}{.86} & \multicolumn{2}{|c|}{$.010^{*}$} & \\
\hline
\end{tabular}

$X$; mean, SD; standard deviation, *p is significant at $5 \%$ level of significance. Different letters in the same column indicate a significant difference between different types of wires (Bonferroni test, $p<.05$ )

TABLE (5): Comparison of springback ratio between different types of wires and effect of different thermocycling conditions.

\begin{tabular}{|c|c|c|c|c|c|c|c|}
\hline & \multicolumn{2}{|c|}{ Control } & \multicolumn{2}{|c|}{$500 \mathrm{TC}$} & \multicolumn{2}{|c|}{$1000 \mathrm{TC}$} & $\begin{array}{l}\text { Repeated measures } \\
\text { ANOVA (p value) }\end{array}$ \\
\hline & $X$ & $S D$ & $X$ & $S D$ & $X$ & $S D$ & \\
\hline SS wire & $20.675 a$ & 1.734 & $5.998 \mathrm{a}$ & .005 & $19.502 \mathrm{a}$ & 6.440 & $<.001 *$ \\
\hline $\mathrm{NiTi}$ & $24.412 \mathrm{a}$ & .775 & $22.752 b$ & 2.376 & $27.425 b$ & 4.533 & .092 \\
\hline $\mathrm{Cu}$ NiTi & $23.380 \mathrm{a}$ & 1.783 & $24.583 b$ & 1.530 & $25.068 \mathrm{~b}$ & .500 & .71 \\
\hline Teflon_NiTi & $33.225 b$ & 4.299 & $27.947 \mathrm{c}$ & 2.409 & $28.648 b$ & 2.022 & .033 \\
\hline $\begin{array}{l}\text { Repeated measures ANOVA } \\
\text { (p value) }\end{array}$ & \multicolumn{2}{|c|}{$.001 *$} & \multicolumn{2}{|c|}{$.001 *$} & \multicolumn{2}{|c|}{$<.001 *$} & \\
\hline
\end{tabular}

$X$; mean, SD; standard deviation, *p is significant at $5 \%$ level of significance. Different letters in the same column indicate a significant difference between different types of wires (Bonferroni test, $p<.05$ )

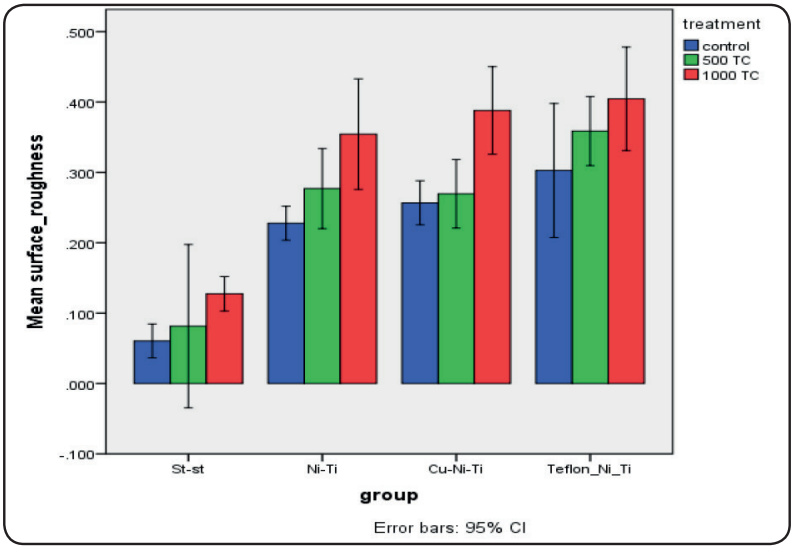

Fig. (2): Multiple comparisons of surface roughness of archwires between different thermocycling regimens.

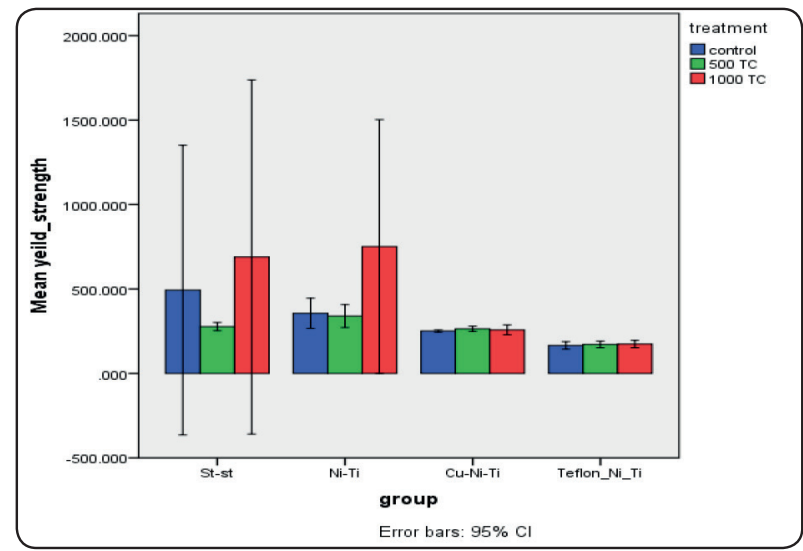

Fig. (3): Multiple comparisons of modulus of elasticity between different thermocycling regimens. 


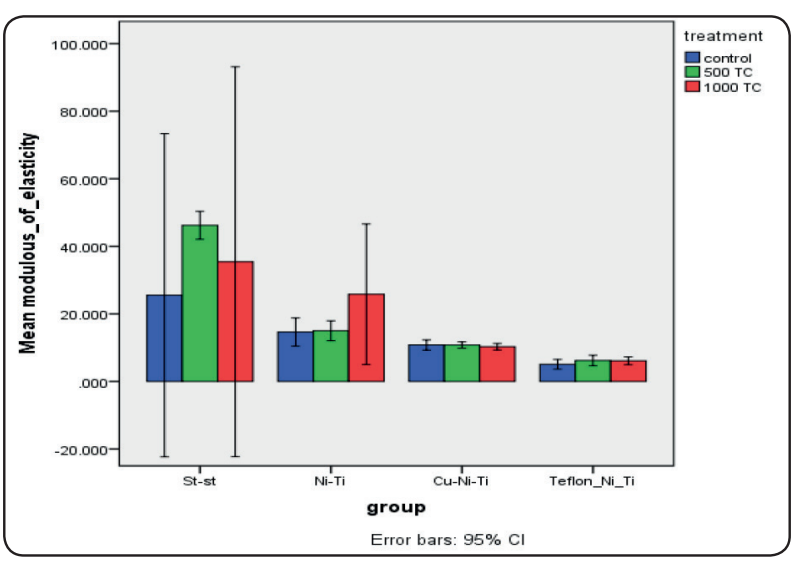

Fig. (4): Multiple comparisons of yield strength between different thermocycling conditions.

\section{DISCUSSION}

Along the orthodontic treatment course, archwires undergo continual and persistent wide temperature alterations in the patient's mouth. These thermal change simply permanent alterations within the wire microstructure. ${ }^{19}$ Thus, this study aims at highlighting and comparing the effect of thermocycling on the surface roughness and springback properties of four different orthodontic archwires including stainless steel, nickel titanium, copper nickel titanium and teflon coated nickel titanium. It was shown that both surface roughness and springback properties of orthodontic archwires could be affected by thermocycling, therefore, the null hypothesis was rejected.

Thermocycling is a widely used aging methodology. The international organization for standardization (ISO) TR 11450 standard (1994) recommended a thermocycling technique including 500 cycles in water between $5^{\circ} \mathrm{C}$ and $55^{\circ} \mathrm{C}$ as a convenient artificial ageing test and numerous studies have been performed according to this ISO standard..$^{20} \mathrm{~A}$ milder temperature range was suggested by Gale and Darvel ${ }^{21}$ who reported that thermal cycles may take place in the oral cavity between 20 and 50 times daily. Accordingly,

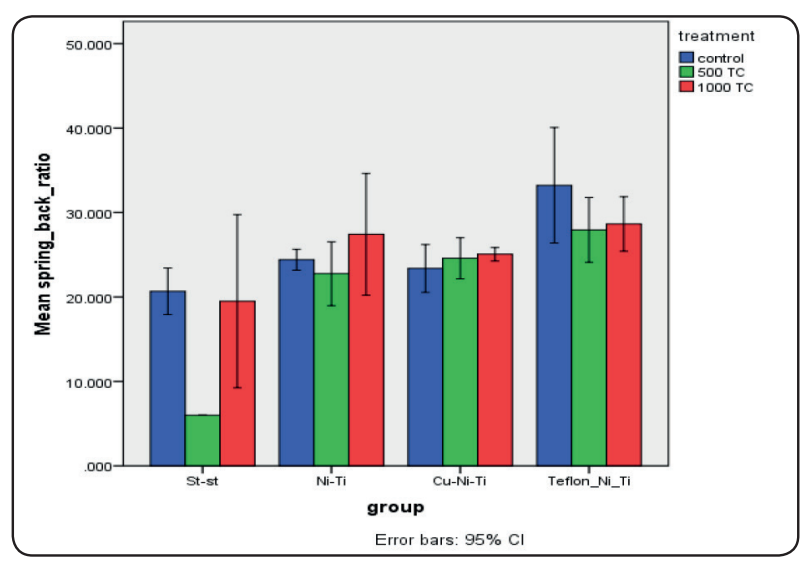

Fig. (5): Multiple comparisons of springback ratio between different thermocycling regimens.

a thermal cycling regimen comprising 500 as well as 1000 cycles between 5 and $55^{\circ} \mathrm{C}$ was utilized in the present study which corresponds to a period of approximately 2 or 4 weeks in vivo, respectively.

A definitive step in the assessment of archwire performance is the estimation of the surface roughness of different wires accessible in the market. ${ }^{16}$ Many studies ${ }^{22-24}$ proved that there is a close association between surface roughness and friction which impacts tooth movement in orthodontic patients. Furthermore, plaque accumulation is affected by surface roughness variation. A good wire must maintain its surface smoothness along the whole period of its application as the chemical changes in the oral cavity may deteriorate the surface characters of the archwire, rendering it very rough over the period of its use and consuming a part of the planned force for tooth movement to overcome the frictional force which is considered of great importance from the clinical orthodontic point of view. ${ }^{10}$ In this study, the surface roughness was determined using surface profilometry, ${ }^{25}$ which has a thin tip utilized to scan the topography in a single line of a predetermined area. Previous studies ${ }^{9,25}$ have demonstrated that profilometry is a useful method for measuring surface roughness. 
The results of the present study showed that the highest surface roughness was noted with Tefloncoated NiTi, followed by NiTi and CuNiTi, while the lowest surface roughness was noted for SS. These findings are in accordance with previous studies ${ }^{16,26,27}$ which demonstrated that SS showed the lowest frictional coefficient and the lowest sliding resistance when used in passive configuration, which could be attributed its low roughness, high hardness and high strength. On the other hand, these data are in contrast with those of Farronato $\mathrm{G}$ et al ${ }^{28}$ and Husmann et $\mathrm{al}^{29}$ who detected that Teflon coated wires generated lower frictional forces compared to their corresponding uncoated wires.

Our results also showed that NiTi wire exhibited higher roughness than CuNiTi wire. This might be related to their crystallographic structure. A phase transformation from the Martensite to the austenite structure can be displayed in Nickel-titanium alloys at a given transformation temperature..$^{30,31}$ The transformation of the alloy composition initiates between room temperature and the employment temperature of $37^{\circ} \mathrm{C},{ }^{33}$ associated with considerable alterations in the structure of the archwire surface. These findings disagree with the results of other studies ${ }^{10,32,33}$ in which $\mathrm{Cu}$ NiTi wires were considered the roughest archwires. They also reported that these wires showed apparent drawing marks and formed microcavities under all degrees of magnification due to pullout of Nickel-titanium particles, which might result in a greater attrition coefficient.

One of the most frequently applied processes in orthodontics is archwire bending. Moreover, springback action that is defined as elastic recovery of the part during unloading, should be considered so that the formed archwire can be produced within acceptable tolerance limits. ${ }^{11}$ In this study, the springback action of the different archwires was calculated based on the ratio YS/E. This ratio reflects the clinical performance of the wire in terms of load deflection rate, working range, stiffness and resilience. Greater springback values indicate the capability to perform large activations resulting in an increase in the working time of the appliance, which denotes fewer archwire changes. Springback is also a measure of how far a wire can be deflected without giving rise to permanent deformation..$^{34,35}$

In this study, three-point bending test was used for determination of the mechanical properties of each of the alloys tested based on the load/displacement curves. The load displacement curves represent true reproduction of the distinctive characters of different alloys, particularly of NiTi alloy which displays different behavior under increasing and decreasing loading. ${ }^{36}$ The results of the present study showed that the highest springback ratio was detected in Teflon coated NiTi, followed by NiTi, then $\mathrm{Cu}$ Ni$\mathrm{Ti}$ and the lowest ratio was observed in SS. This was in consistency with Gilbert ${ }^{5}$ who reported that the alloy of nickel and titanium was shown to have a lower modulus of elasticity and greater spring back compared to stainless steel.

Our results also showed that after thermocycling (500 TC), the springback action of SS, NiTi and Teflon coated wires was decreased, while after 1000 TC, the spring back action of NiTi was improved. Isac et.al ${ }^{37}$ explained the decrease in the springback action on the basis of work hardening as a result of repetitive intraoral thermal and mechanical stresses to which archwires were subjected. Benzin and Roberts $^{38}$ examined the influence of thermocycling on nickel-titanium archwire phase transformation. They demonstrated that thermal cycles induce both qualitative and quantitative alterations in the phase transformation rate. These alterations in the transformation behavior develop as a result of increasing dislocations, which were recorded after few cycles. On the reverse, after higher cycles, they observed that NiTi archwires did not display phase transformation changes because the generation of dislocations was thought to be impeded by the presence of precipitates (Ti2Ni and $\mathrm{Ti} 3 \mathrm{Ni} 4)$. Numerous studies ${ }^{39,40}$ reported that the esthetic coated nickel-titanium wires subjected to the intraoral environment, undergo a great deterioration in the mechanical properties due to prominent degeneration of the coating. 
In the present study, the slight improvement in springback action of CuNiTi could be attributed to the incorporation of copper that was effecient to restrict the stress hysteresis and to stabilize the superelasticity features. ${ }^{41}$

\section{CONCLUSIONS}

Based on the results, the following conclusions can be made:

1. The as-received SS wires exhibited the least surface roughness, while Teflon-coated NiTi wires exhibited the highest values.

2. After thermocycling, the surface roughness of all types of archwires was increased; this increase was insignificant after 500 cycles and significant after 1000 cycles.

3. The as-received Teflon-coated wires showed the highest spring back ratio, while the lowest ratio was detected in SS.

4. After 500 thermal cycles, the springback properties were significantly decreased in stainless steel, NiTi and Teflon-coated NiTi wires only.

5. After 1000 thermal cycles, the springback properties were significantly decreased in stainless steel and Teflon-coated archwires, while increased in NiTi compared to control group.

\section{Conflict of interest}

The authors declared no potential conflicts of interest.

\section{REFERENCES}

1. Proffit WR. Contemporary Orthodontics. $2^{\text {nd }}$ ed. St. louis: Mosby, 1993: p. 289.

2. Eliades T. Orthodontic materials research and applications: part 2. Current status and projected future developments in materials and biocompatibility. Am J Orthod Dentofac Orthop 2007; 131:253-62.

3. Verstrynge A, Van Humbeeck J, Willems G. In-vitro evaluation of the material characteristics of stainless steel and beta-titanium orthodontic wires. Am J Orthod Dentofac Orthop 2006; 130:460-70.

4. Schneevoigt R, Haase A, Eckardt VL, Harzer W, Bourauel C. Laboratory analysis of superelastic NiTi compression springs. Med Eng Phys 1999; 21:119-25.

5. Gilbert J. Thermal Properties of Copper Nickel-Titanium Orthodontic Archwires. Marquette University 2016.

6. Petoumenou E, Arndt M, Keilig L, Reimann S, Hoederath $\mathrm{H}$, Eliades T, et al. Nickel concentration in the saliva of patients with nickel-titanium orthodontic appliances. Am J Ortho Dentofac Orthop 2009; 135:59-65.

7. Huang ZMet al.Fabrication of a new composite orthodontic archwire and validation by a bridging micromechanics model. Biomaterials 2003; 24:2941-53.

8. Kusy RP. A review of contemporary archwires: their properties and characteristics. Angle Orthod 1997; 67:197207.

9. Wichelhaus A, Geserick M, Hibst R, Sander FG. The effect of surface treatment and clinical use on friction in NiTi orthodontic wires. Dent Mater 2005; 21:938-45.

10. Yousif AA, El-Karim UM. Microscopic study of surface roughness of four orthodontic arch wires. Tanta Dent J 2016; 13:199-207.

11. Jin-gang J, Zhao W, Yong-de Z, Ji-xiong J, Suo-liang N, Yi L. Study on springback properties of different orthodontic archwires in archwire bending process. Int $\mathrm{J}$ Control Autom 2014; 7:283-90.

12. Eliades $\mathrm{T}$, Bourauel $\mathrm{C}$. Intraoral aging of orthodontic materials: the picture we miss and its clinical relevance. Am J Ortho Dentofac Orthop 2005; 127:403-12.

13. Helvatjoglu-Antoniades M, Koliniotou-Kubia E, Dionyssopoulos P. The effect of thermal cycling on the bovine dentine shear bond strength of current adhesive systems. J Oral Rehabil 2004; 31:911-7.

14. Lombardo L, Toni G, Stefanoni F, Mollica F, Guarneri MP, Siciliani G. The effect of temperature on the mechanical behavior of nickel-titanium orthodontic initial archwires. Angle Orthod 2012; 83:298-305.

15. Perinetti G, Contardo L, Ceschi M, Antoniolli F, Franchi L, Baccetti T, Di Lenarda R. Surface corrosion and fracture resistance of two nickel-titanium-based archwiresinduced by fluoride, $\mathrm{pH}$, and thermocycling. An in vitro comparative study. Eur J Orthod 2012; 34:1-9. 
16. D’Anto` V, Rongob R, Ametranoa G, Spagnuoloa G, Manzoa P, Martina R, et al. Evaluation of surface roughness of orthodontic wires by means of atomic force microscopy. Angle Orthod 2012; 82:922-8.

17. ISO E. 4287-Geometrical Product Specifications (GPS)Surface Texture: Profile Method-Terms, Definitions and Surface Texture Parameters. International Organization for Standardization, Geneve. 1997.

18. Hammada SM, Al-Wakeel EE, Gad E. Mechanical properties and surface characterization of translucent composite wire following topical fluoride treatment. Angle Orthod 2012; 82:8-13

19. Berzins DW, Roberts HW. Phase transformation changes in thermocycled nickel-titanium orthodontic wires. Dent Mater 2010 Jul 1; 26 (7):666-74.

20. The ISO TR, " 11450 standard. International organization for standardization,” ISO TR 11405, 1994, Dental materials guidance on testing of adhesion to tooth structure.

21. Gale MS, Darvell BW. Thermal cycling procedures for laboratory testing of dental restorations. J Dent 1999; 27:89-99.

22. Downing A, McCabe J, Gordon P. A study of frictional forces between orthodontic brackets and archwires. Br J Orthod 1994; 21:349-57.

23. Bazakidou E, Nanda RS, Duncanson MG Jr, Sinha PE. Valuation of frictional resistance in esthetic brackets. Am J Orthod Dentofac Orthop 1997; 112:138- 44.

24. Nanda RS. Biomechanics and esthetic strategies in clinical orthodontics. St Louis, MO: Elsevier; 2005.

25. Bourauel C, Fries T, Drescher D, Plietsch R. Surface roughness of orthodontic wires via atomic force microscopy, laser specular reflectance, and profilometry. Eur J Orthod 1998; 20:79-92.

26. Choi S, Hwang EY, Park HK, Park YG. Correlation between frictional force and surface roughness of orthodontic archwires. Scanning 2015; 37:399-405.

27. Keith O, Kusy RP, Whitley JQ. Zirconia brackets: an evaluation of morphology and coefficients of friction. Am J Orthod Dentofac Orthop. 1994; 106:605-14.

28. Farronato G, Maijer R, Carìa MP, Esposito L, Alberzoni $\mathrm{D}$, Cacciatore $\mathrm{G}$. The effect of Teflon on coating on the resistance to sliding of orthodontic archwires. Eur J Orthod 2012; 34:410-7.
29. Husmann P, Bourauel C, Wessinger M, Jäger A. The frictional behavior of coated guiding archwires. J Orofac Orthop 2002; 63:199-211.

30. Buehler WJ, Gilfrich JV, Wiley RC. Effect of low temperature phase changes on the mechanical properties of alloys near composition of TiNi. J Appl Phys.1963; 34:1475-84.

31. Andreasen GF, Brady PR. A use hypothesis for 55 nitinol wire for orthodontics. Angle Orthod 1972; 42:172-7.

32. Gravina MA, Cristiane C, Carlos N. Mechanical properties of NiTi and CuNiTi wires used in orthodontic treatment. Part 2: microscopic surface appraisal and metallurgical characteristics. Dental Press J Orthod. 2014; 19:69-76.

33. Fischer-Brandies H, Es-Souni M, Kock N, Raetzke K, Bock O. Transformation behavior, chemical composition, surface topography and bending properties of five selected 0.016 " $\times 0.022$ " NiTiarchwires. J Orofac Orthop 2003; 64:88-99.

34. Thurow RC Edgewise Orthodontics. $4^{\text {th }}$ Edition 1982. St. Louis. The CV Mosby Company.

35. Bradley TG, Brantley WA, Culbertson BM. Differential Scanning Calorimetry (DSC) analyses of superelastic and non superelastic orthodontic wires. Am J Orthod Dentofac Orthop. 1996; 109:589-97.

36. Pernier C, Grosgogeat B, Ponsonnet L, Benay G, Lissac M. Influence of autoclave sterilization on the surface parameters and mechanical properties of six orthodontic wires. Eur J Orthod 2005; 27:72-81.

37. Isac J, Mahendra S, Chandrashekar BS, Reddy VP, Ramesh Kumar PC, ShettyBM. Effects of clinical recycling on mechanical properties of three commonly used types of orthodontic archwires. Saudi J Oral Dent Res 2016; 1:124-36.

38. Berzins DW, Roberts HW. Phase transformation changes in thermocycled nickel-titanium orthodontic wires. Dent Mater. $2010 \mathrm{Jul}$ 1; 26(7):666-74.

39. Elayyan F, Silikas N, Bearn D. Mechanical properties of coated superelastic archwires in conventional and selfligating orthodontic brackets. Am J Orthod Dentofac Orthop. 2010 Feb 1; 137 (2):213-7.

40. Da Silva DL, Mattos CT, de Araújo MV, de Oliveira Ruellas AC. Color stability and fluorescence of different orthodontic esthetic archwires. The Angle Orthod. 2013; 83(1):127-132.

41. Gil FG, Solano E, Pena J, Engel E, Mendoza A, Planell JA. Microstructural, mechanical and cititoxicity evaluation of different NiTi and NiTiCu shape memory alloys. J Mater Sci Mater Med 2004; 15:1181-5. 